\title{
A GLOBALIZAÇÃO E O DIREITO COSMOPOLITA
}

\author{
Globalization and Cosmopolitan Law ${ }^{1}$
}

\begin{abstract}
Alexandre Sales Cabral Arlota ${ }^{2}$
Sumário: 1 Introdução. 2 Desconcentração concentrada e a criação de novas diferenças. 3 Características da contemporaneidade e o direito. 4 Conclusão. Referências.
\end{abstract}

\begin{abstract}
Resumo: Este artigo visa a traçar um panorama geral do fenômeno da globalização, e delinear como característica marcante a difusão de elementos de estraneidade, a permear as relações interpessoais. No esteio da internacionalização, estabelecem-se relações atípicas, situações da vida privada a que afetam elementos estrangeiros, desestruturando-se a normalidade decorrente de vínculo exclusivo com um único Estado. Associada à pluralidade, a cognoscibilidade se apresenta como traço definidor da contemporaneidade, sendo que a incorporação de distintas áreas no modelo pós-fordista de produção depende da revelação dos atrativos daquele território, de modo que se evidencie o que ele pode oferecer à ordem global. A globalização, por sua vez, ao mesmo tempo em que permite a integração de novos territórios à ordem internacional, afasta outros tantos, aprofundando assimetrias já existentes, em uma dialética centrípeta e centrífuga. Por sua vez, a ação das transnacionais, desfidelizadas e desenraizadas, leva com alguma reincidência a lógicas fragmentadas, o que facilita a desestabilização dos laços de solidariedade que ligam os povos e os territórios. A emergência de um direito efetivamente cosmopolita fundase no reconhecimento de que muitos dos desafios contemporâneos não podem ser satisfatoriamente enfrentados de forma desconcertada e, simultaneamente, procura retomar o fundamento ético que se esvai das relações interestatais e interpessoais.
\end{abstract}

Palavras-chave: Globalização. Fragmentação territorial. Pós-fordismo. Sujeitos de direito internacional. Transnacionais. Direito cosmopolita.

\begin{abstract}
On the present academic paper, the author aims to outline the phenomenon of globalization and to assess how the spreading of extraneous elements permeates interpersonal relationships. In the wake of internationalization, atypical relationships are established, situations affected by foreign elements, disrupting the normality due to a unique bond with a single state. Associated with the plurality, cognoscibility is presented as a defining feature of contemporary society, especially because the post-Fordism model depends on the revelation of new areas for investments, in order to evidence what they can offer to this new global order. Globalization allows the integration of new territories, as further precludes others, deepening existing asymmetries in a centripetal and centrifugal dialectic. In turn, the action of transnationals, non-rooted and disloyal agents, leads to a fragmented logic, what facilitates the destabilization of bonds of solidarity that bind the peoples and territories. The emergence of a truly cosmopolitan law is founded on the recognition that many of today's challenges cannot be adequately addressed in a staggered manner and simultaneously seeks to resume the ethical foundation that now fades from interstate and interpersonal relationships.
\end{abstract}

Keywords: Globalization. Territorial fragmentation. Post-Fordism. International Law subjects. Transnationals. Cosmopolitan law.

\footnotetext{
${ }^{1}$ DOI deste artigo: http://dx.doi.org/10.12957/cosmopolitan.2014.10023.

2 Professor Substituto de Direito Internacional Privado e Direito Civil da Universidade Federal do Rio de Janeiro (UFRJ); Mestre em Direito Internacional - UERJ; Graduado em Direito - UERJ; Secretário Geral da Comissão de Direito Marítimo, Portuário e do Mar - OAB-RJ (mandato triênio 2013-2016); Membro da AIPN - Association of International Petroleum Negotiators; Membro do IBP - Instituto Brasileiro de Petróleo, Gás e Biocombustíveis; Membro da International BAR Association; Membro do Instituto Brasileiro de Direito da Construção - IBDIC.
} 


\section{INTRODUÇÃO}

A globalização não se constitui como fenômeno recente; sendo, em verdade, o desdobramento de processo imemorial de internacionalização da atividade humana ${ }^{3}$, o qual se intensificou no último século, em decorrência da introdução de novos meios de comunicação e transporte, bem como do incremento da dinamicidade daqueles já existentes. 4

Inclui-se, nas principais repercussões da intensificação dos fluxos de bens, pessoas e informações e da aceleração do contato entre diferentes nações, o forjar de uma nova divisão internacional do trabalho: se, no passado, as economias de aglomeração foram preponderantes para o sucesso da onda industrializante, amplamente dependente da proximidade a mercados consumidores, a centros produtores de energia e a locais concentradores de mão de obra disponível; na atual fase de internacionalização, tornou-se possível a descentralização espacial da produção - a qual se orienta, precipuamente, pela busca de maior flexibilidade trabalhista, ambiental e fiscal. 5

3Para Rudolph Dolzer e Christoph Schreuer, a $1^{\text {a }}$ e a $2^{\text {a }}$ Guerras Mundiais marcaram o refluxo de intensa onda de internacionalização da economia, a qual seria retomada apenas em 1945: "Generalizando-se, o papel e a importância dos investimentos internacionais aumentaram, na modernidade, em duas grandes ondas. Na primeira, de 1870 a 1914, uma nova dimensão de mobilidade internacional levou ao crescimento dos investimentos internacionais. Em uma perspectiva legal, essa profunda alteração foi acompanhada por leis internas, que abriram as fronteiras econômicas, sobretudo em face da ausência de acordos internacionais, os quais se limitavam às telecomunicações e à facilitação do transporte, essa primeira onda fundou-se na mudança da dinâmica de relacionamento entre as economias nacionais. Esse primeiro período moderno de internacionalização econômica foi suspenso em 1914, pela I Guerra Mundial e os subsequentes problemas econômicos da década de 1920; e, depois, pela II Guerra Mundial. Após 1945, o ritmo de investimentos estrangeiros se acelerou lentamente e chegou a um primeiro pico nos anos de 1990, quadruplicando entre 1990 e 2000, novamente estimulados pelo desenvolvimento tecnológico e pela redução dos custos de transporte." (Tradução livre do Autor) DOLZER, Rudolph e SCHREUER, Christoph. Principles of International Investment Law. p. 01. Outros autores identificam as décadas de 1910 a 1950 como um interlúdio protecionista no processo de internacionalização, o qual remeteria a séculos anteriores: "Globalists regard the forty-year interlude of protectionism (c. 1910-1950) as a temporary detour from a longer historical trend towards the construction of a single integrated world economy [...]. From this perspective [...] contemporary economic globalization continues the universalizing project of modernity launched several centuries ago." BAYLIS, John; SMITH, Steve e OWENS, Patricia. The Globalization of World Politics. p. 455. Também para Franz Benda-Beckman, Keebet Von Benda-Beckman e Anne Griffiths, o atual incremento dos laços internacionais é resultado de longa trajetória, que remonta à Antiguidade Clássica. Para os autores, a leitura histórica permite entender a globalização como o desdobramento de um processo que, embora marcado por influxos, não constitui fenômeno singular da contemporaneidade. BENDA-BECKMAN, Franz; VON BENDA-BECKMAN, Keebet Von; e GRIFFITHS, Anne. Mobile People, Mobile Law: An Introduction. In Mobile People, Mobile Law: Expanding Legal Relations in a Contracting World. p. 118.

4 "A globalização é, de certa forma, o ápice do processo de internacionalização do mundo capitalista." SANTOS, Milton. Por Uma Outra Globalização. p. 17.

5 "Countless discussions of globalization have highlighted its economic aspects. For example, Milton Friedman, a Nobel-Prize-winning economist, remarks that it has become possible to 
Além de promover uma frouxidão regulatória, os Estados se lançam ao oferecimento de vantagens locacionais. Nessa busca ativa por se tornar o destino preferencial de dada parcela de capital, promove-se ferrenha competição, e desestruturam-se os laços de solidariedade que, antes, ligavam diferentes territórios e/ou unidades políticas a um Estado ou comunidade.

Ao Estado caberá conceber arranjos institucionais e socializar os custos de infraestrutura e de segurança necessários ao funcionamento de setores inseridos na economia globalizada. Uma prova disso é a promoção por Estados nacionais da 'guerra dos lugares'. É hoje algo comum, com governos a oferecerem vantagens fiscais e locacionais diversas para a implantação de investimentos e capitais externos às cidades, regiões e países. ${ }^{6}$

Se, por um lado, esse novo arranjo, denominado de pós-fordista, permite a produção maciça de bens industriais nos países periféricos, não se mostrou o mesmo capaz de estimular o equilíbrio entre os povos. Inobstante o vetor homogeneizante que se propõe a revelar áreas distantes7, evidenciando suas potencialidades de produção, incluindo-as no mercado global, a inserção da periferia se dá, com frequência, de forma subordinada e hierarquizada, conforme acurada crítica de Milton Santos.

Um mercado avassalador dito global é apresentado como capaz de homogeneizar o planeta quando, na verdade, as diferenças locais são aprofundadas. ${ }^{8}$

O meio técnico-científico-informacional não se impõe igualmente sobre o território [...] cada ponto do território modernizado é chamado a oferecer aptidões específicas à produção. É uma nova divisão territorial, fundada na ocupação de áreas até então periféricas e na remodelação de regiões já ocupadas. ${ }^{9}$

Por concentrarem a produção de conhecimento técnico e científico, os países centrais mantêm-se como os mais relevantes pontos de conexão na

produce a product anywhere, using resources from anywhere, by a company located anywhere". BAYLIS, John; SMITH, Steve e OWENS, Patricia. The Globalization of World Politics. p. 452.

6 PEREIRA, João Eduardo de Alves. Geopolítica e Direito Internacional no Século XXI. In DIREITO, Carlos Alberto Menezes, TRINDADE, Antonio Augusto Cançado, PEREIRA, Antonio Celso Alves (Org.). Novas Perspectivas do Direito Internacional Contemporâneo: Estudos em Homenagem ao Professor Celso D. de Albuquerque Mello. p. 872 e 873.

7 "A cognoscibilidade do planeta constitui dado essencial à operação das empresas e à produção do sistema histórico atual.” SANTOS, Milton. Por Uma Outra Globalização. p. 33. Em trecho seguinte da mesma obra, o autor retoma essa ideia: "A vida assim realizada por meio dessas técnicas é, pois, cada vez menos subordinada ao aleatório e cada vez mais exige dos homens comportamentos previsíveis." Idem. p. 63.

${ }^{8}$ Idem. p. 19.

9 SANTOS, Milton e SILVEIRA, Maria Laura. O Brasil, Território e Sociedade no Início do Século XXI. p. 105. 
estrutura internacional. Descentraliza-se a produção; mas, não, a riqueza. Similarmente, o poder de mando continua a ser irradiado do centro - ou sede do ator econômico, e não de suas filiais, espalhadas pelo mundo. Assim, subsiste a diferença entre os "locais que mandam e aqueles que obedecem". ${ }^{10}$

Não obstante os reiterados esforços dos países hospedeiros em refinar sua legislação interna e desenvolver novas modalidades de atração do capital estrangeiro - inclusive a partir do aporte direto de capital público para o estabelecimento da infraestrutura necessária à ação do ente estrangeiro - há dificuldades na ruptura do caráter circunstancial e na permanência dos investimentos vindos do exterior. A seletividade das fronteiras nacionais, porosas aos voláteis fluxos financeiros, e rígidas aos demais, promove uma ação disruptiva e privilegia a especulação improdutiva. ${ }^{11}$

Mais que isso, há subversão do papel do Estado, o qual, como defende João Eduardo de Alves Pereira, pretere o bem-estar da população local e se dedica à criação de aptidões no território para as transnacionais.

A economia atual necessita de áreas contínuas, dotadas de infraestrutura coletivas, unitárias, realmente indissociáveis quanto ao seu uso produtivo. Mas esse equipamento chamado coletivo é, na verdade, feito para serviço de empresas hegemônicas. Construídas com dinheiro público, essas infraestruturas aprofundam o uso seletivo do território, deixando excluída ou depreciada a maior parte da economia e da população. ${ }^{12}$

Habitualmente, o capital não se fideliza ao território, e segue obedecendo às diretrizes emanadas dos centros. As transnacionais ${ }^{13}$, destituídas de lealdade

\footnotetext{
10 "Se a produção se fragmenta tecnicamente, há, de outro lado, uma unidade política de comando. Essa unidade política de comando funciona no interior das firmas, mas não há propriamente uma unidade de comando no mercado global. Cada empresa comanda as respectivas operações dentro da sua respectiva topologia, isto é, do conjunto de lugares de sua ação, enquanto a ação dos Estados e das instituições supranacionais não basta para impor uma ordem global." Idem. p 27. Em outro trecho da mesma obra: "Levando-se em consideração o acúmulo de funções diretoras em certos lugares e a sua falta na maioria dos demais, será lícito admitir que há espaços que comandam e espaços que obedecem? [...] pode-se dizer que há espaços que comandam e espaços que obedecem, mas o comando e a obediência resultam de um conjunto de condições [...]." Idem. p. 264 e 265.

${ }_{11}$ De fato, as fronteiras facilitam a entrada de fluxos financeiros, de caráter essencialmente especulativo; mas dificultam a imigração de pessoas, sobretudo aquelas sem qualificação técnica. É essa seletividade das fronteiras aos diferentes fluxos que Milton Santos qualifica como ora porosas, ora rígidas. SANTOS, Milton. Por Uma Outra Globalização. p. 83 e 84.

12 PEREIRA, João Eduardo de Alves. Geopolítica e Direito Internacional no Século XXI. In DIREITO, Carlos Alberto Menezes, TRINDADE, Antonio Augusto Cançado, PEREIRA, Antonio Celso Alves (Org.). Novas Perspectivas do Direito Internacional Contemporâneo: Estudos em Homenagem ao Professor Celso D. de Albuquerque Mello. p. 884.

${ }^{13}$ Seguimos a linha capitaneada por Celso D. de Alburquerque Mello, também eleita por outros ilustres autores, para quem a adoção do termo transnacional justifica-se, porquanto há uma nacionalidade da sede controladora. MELLO, Celso D. de Albuquerque. Direito Internacional
} 
aos locais em que atuam, emergem, então, como um dos principais veículos desta onda de desconcentração espacial da produção.

Os lucros, por sua vez, revertem-se da periferia ao centro tradicional (Estados Unidos, Europa e Japão), com a admissão de alguns poucos membros (China, Coréia do Sul, Cingapura e outras economias emergentes do Sudeste Asiático).

\section{DESCONCENTRAÇÃO CONCENTRADA E A CRIAÇÃO DE NOVAS DIFERENÇAS}

Se o desejo homogeneizante das forças econômicas expande, com sucesso, a sociedade de consumo, implicando na reprodução de modelos comportamentais cunhados nos países centrais, a que se associa a desconstrução de formas sociais tradicionais, esse processo não se dá na mão única da uniformização. Paralelamente, aprofundam-se diferenças pré-existentes e se criam outras, amparadas, sobretudo, na difusão assimétrica das técnicas. ${ }^{14}$

Não se pode deixar de reconhecer que dos centros de onde partem os principais vetores de uniformização - ao mesmo tempo em que transformam o mundo à sua imagem e semelhança - são também moldados por influências que lhe são alienígenas. Tampouco se pode dizer que toda e qualquer área periférica habilitar-se-á à integração, ainda que subordinada, na ordem econômica internacional: apenas as regiões em que se difundem os meios técnicos tornar-

Econômico. p. 105 e RIBEIRO, Marilda Rosado de Sá. As Empresas Transnacionais e os Novos Paradigmas do Comércio Internacional. In DIREITO, Carlos Alberto Menezes, TRINDADE, Antonio Augusto Cançado, PEREIRA, Antonio Celso Alves (Org.). Novas Perspectivas do Direito Internacional Contemporâneo: Estudos em Homenagem ao Professor Celso D. de Albuquerque Mello. p. 465.

${ }^{14}$ Apesar de reconhecer a potencialidade de homogeneização, Milton Santos defende que a difusão seletiva de técnicas pelo território resulta no aprofundamento de diferenças já existentes e no estabelecimento de novas: "Os homens não são igualmente atores desse tempo real. Fisicamente, isto é, potencialmente, ele existe para todos. Mas efetivamente, isto é, socialmente, ele é excludente e assegura exclusividades, ou, pelo menos, privilégios de uso. Como ele é utilizado por um número reduzido de atores, devemos distinguir entre a noção de fluidez potencial e a noção de fluidez efetiva. Se a técnica cria aparentemente para todos a possibilidade da fluidez, quem, todavia, é fluido realmente?" SANTOS, Milton. Por Uma Outra Globalização. p. 28 e 29. Marilda Rosado de Sá Ribeiro e Bruno Almeida também tratam da globalização como estimuladora de novas diferenças: "Outro aspecto corriqueiramente atribuído a esta conjuntura é a chamada 'eliminação das fronteiras', pressupondo a criação de um novo cenário mundial onde os indivíduos estariam cada vez mais próximos. Os valores imbuídos em expressões amplamente utilizadas tais como 'aldeia global' ou 'comunidade internacional' podem levar à conclusão equivocada de que este processo seja natural ou de que não tenha contribuído para o agravamento dos problemas existentes na ordem mundial hodierna." RIBEIRO, Marilda Rosado de Sá; ALMEIDA, Bruno de. Do Conflito Aparente de Normas no Espaço à Cinemática Jurídica Global: Conteúdo do Direito Internacional Privado Contemporâneo. p. 5. 
se-ão aptas a receber os investimentos estrangeiros, criando, a partir de um processo de desconcentração-concentrada, macroáreas receptoras de investimento. Isto é, apesar de as novas técnicas se espalharem pelo território de forma mais ampla que no passado, persiste uma tendência de concentração nas regiões tradicionais, pois lá é o território mais apto a responder às demandas dos atores externos. Sobre essa dinâmica, posicionam-se Milton Santos e Maria Laura Silveira:

Como em todos os períodos, o novo não é completamente difundido no território. Todavia os objetos técnico-informacionais conhecem uma difusão mais generalizada e mais rápida do que os objetos técnicos de pretéritas divisões territoriais do trabalho. A área de abrangência dos objetos atuais e das ações associadas é mais ampla. Isso não impede que tantos objetos como ações modernas tendam a concentrar-se em certos pontos e áreas do país. Eis uma das interpretações possíveis da existência, de um lado, de uma Região Concentrada, de apenas manchas e pontos desse meio técnico-científico-informacional, mais ou menos superposto a outras divisões territoriais do trabalho [...].15

A interconexão entre os diferentes pontos espaciais se dá por meio de redes sobrepostas (ligação reticular), que se conectam aos centros. ${ }^{16}$ Assim, a admissão de pontos esparsos de dado território à ordem global pode, ao mesmo tempo, aprofundar o alijamento dos demais - aos quais as modernas técnicas não alcançaram. Consequentemente, a globalização suscita e se manifesta por tendências contraditórias, permitindo a conexão de diferentes áreas e a virtual supressão das distâncias; mas, alienando outros tantos territórios. ${ }^{17}$

Com a globalização são instalados numerosos nexos extravertidos, na medida em que, havendo a política econômica deixado de privilegiar o mercado interno, a necessidade de exportar conduz a uma lógica competitiva que vai privilegiar relações externas comandadas pelas empresas globais responsáveis pela demanda.

$\mathrm{Na}$ medida em que, com o mercado chamado global, cada empresa busca satisfazer-se nos lugares onde as respostas aos seus clamos é mais adequada, tal demanda é errática e o território passa a ter, nas

${ }^{15}$ SANTOS, Milton. Por Uma Outra Globalização. p. 140.

16 OLIVEIRA, Henrique Altemani e LESSA, Antônio Carlos. Política Internacional Contemporânea: mundo em transformação. p. 5 .

17 "Essas técnicas da informação (por enquanto) são apropriadas por alguns Estados e por algumas empresas, aprofundando assim os processos de criação de desigualdades." SANTOS, Milton. Por Uma Outra Globalização. p. 39. "Em nossa época, o que é representativo do sistema de técnicas atual é a chegada da técnica da informação, por meio da cibernética, da informática, da eletrônica. Ela vai permitir duas grandes coisas: a primeira é que as diversas técnicas existentes passam a se comunicar entre elas. A técnica da informação assegura esse comércio, que antes não era possível. Por outro lado, ela tem um papel determinante sobre o uso do tempo, permitindo, em todos os lugares, a convergência dos momentos, assegurando a simultaneidade das ações e, por conseguinte, acelerando o processo histórico. [...] Quando um determinado ator não tem condições para mobilizar as técnicas consideradas mais avançadas, torna-se, por isso mesmo, um ator de menor importância no período atual.” Idem. p. 25 
áreas atingidas por esse tipo de relações, uma dinâmica [...] que é também alienada, já que não precisa ter correspondência com os interesses da sociedade local ou nacional. Novas formas de compartimentação do território ganham relevo e são capazes de impor distorções ao seu comportamento: são as novas caras da fragmentação territorial. ${ }^{18}$

$\mathrm{O}$ fato de que aqueles pontos, que se ligam às redes internacionais, obedeçam, quase que instantaneamente, aos interesses externos - funcionando a partir de motivações exógenas - implica na ruptura da integração no seio social. ${ }^{19}$

Não por acaso, recrudesceram, nas últimas décadas, movimentos emancipacionistas como o Separatista Basco, dirigido à formação de um Estado Catalão. Em apertada simplificação, observa-se a superveniente incapacidade de determinadas áreas identificarem-se com outras que compõem um mesmo território. ${ }^{20} \mathrm{O}$ próprio terrorismo poderia ser interpretado, sob essa ótica, como movimento de reação à tendência uniformizadora contemporânea de imposição dos valores ocidentais e, por conseguinte, da dissolução de tradições históricas. ${ }^{21}$

Há, portanto, umbilicalmente associada ao movimento de unificação de mercado a fragmentação territorial. Nesse sentido, contrapõem-se aos vetores

${ }^{18}$ SANTOS, Milton e SILVEIRA, Maria Laura. O Brasil, Território e Sociedade no Início do Século XXI. p. 254.

19 "A globalização traz uma tendência de fragmentação territorial, segregando áreas, cidades e regiões ricas e modernizadas daquelas que vão se tornando cada vez mais pobres e incapazes de acompanhar um mundo marcado, entre outros aspectos, pelo crescente poder da mídia internacional. Isto atinge diretamente o Estado nacional, que pode assistir ao surgimento de forças centrífugas que põem em risco sua integridade.” PEREIRA, João Eduardo de Alves. Geopolítica e Direito Internacional no Século XXI. In DIREITO, Carlos Alberto Menezes, TRINDADE, Antonio Augusto Cançado, PEREIRA, Antonio Celso Alves (Org.). Novas Perspectivas do Direito Internacional Contemporâneo: Estudos em Homenagem ao Professor Celso D. de Albuquerque Mello. p. 872 e 873.

${ }^{20} \mathrm{O}$ impulso a racionalidades externas, em detrimento de uma visão localista, é, com extrema propriedade, denominado por Milton Santos de esquizofrenia do território: "O território tanto quanto o lugar são esquizofrênicos, porque de um lado acolhem os vetores da globalização, que neles se instalam para impor sua nova ordem, e, de outro lado, neles se produz uma contra-ordem [...].” SANTOS, Milton. Por Uma Outra Globalização. p. 114.

${ }^{21}$ HOBSBAWM, Eric. Globalização, Democracia e Terrorismo. p. 94 a 96. Especificamente sobre a Revolução Iraniana e o aprofundamento do fundamentalismo religioso, Henrique Altemani de Oliveira e Antônio Carlos Lessa expõem: "O Irã significou um desafio para o Ocidente sobretudo pela sua capacidade de congregar grande número de pessoas identificadas com o fundamentalismo islâmico e por ter assumido um caráter declaradamente antiocidental. Isso se deve ao fato de que por muito tempo o destino do Irã e de todo o Oriente Médio foi determinado a partir de fora, sob influência europeia e norte-americana. Ademais, a Revolução foi francamente uma reação associada a uma profunda rejeição aos valores relacionados ao Ocidente. Mas não é só isso. O objetivo dos aiatolás era também purificar o próprio mundo islâmico." In OLIVEIRA, Henrique Altemani; LESSA, Antônio Carlos. Política Internacional Contemporânea: mundo em transformação. p. 112. 
homogeneizantes manifestações de rejeição e resistência, irredentas à desestabilização das formas de vida tradicionais. ${ }^{22}$

\section{CARACTERÍSTICAS DA CONTEMPORANEIDADE E O DIREITO}

O primeiro elemento da sociedade pós-moderna que afeta o Direito é a pluralidade ou o pluralismo: pluralidade de sujeitos, pluralidade de agentes no mercado, pluralidade de vínculos obrigacionais. ${ }^{23}$

Neste sentido, mesmo uma família, descrita como típica - aquela formada por pessoas de uma só nacionalidade, domicílio em um só país, adeptas de uma só religião, criadas em uma só cultura, a manter contato aparente com um só Estado soberano - seria, na visão atual, uma pluralidade, face aos diferentes sujeitos que a integram e aos interesses e direitos que ali coexistem e, por vezes, colidem. Há, ainda, relações outras, as quais apresentam elementos de internacionalidade, a romper a ficção de tipicidade ou normalidade do vínculo com um único Estado ou dado ordenamento jurídico. De fato, o incremento da internacionalidade traduz-se na difusão desses elementos de estraneidade a permearem as relações interpessoais; sendo que, com maior frequência, observam-se as chamadas relações atípicas. ${ }^{24}$

Em adição à aplicação de regras de diferentes ordenamentos jurídicos, justificável, e até recomendável; ressalta-se, em meio a relações que crescentemente comportam elementos internacionais, outra característica: a emergência de novos atores, capazes de contrair obrigações e de titularizar direitos no plano internacional, sendo - portanto - reconhecidos como sujeitos de Direito Internacional. 25

\footnotetext{
22 "Com a globalização, todo e qualquer pedaço da superfície da Terra se torna funcional às necessidades, usos e apetites de Estados nesta fase da história. [...] Redefinida em função das características de uma época, a compartimentação atual distingue-se daquela do passado e frequentemente se dá como fragmentação. [...] Já a fragmentação revela um cotidiano em que há parâmetros exógenos, sem referência ao meio." SANTOS, Milton. Por Uma Outra Globalização. p. 81 .

${ }^{23}$ JAYME, Erik. Curso de Haia de 1995 - Identité Culturelle et Intégration: Le Droit Internationale Privé Postmoderne.

24 MARQUES, Cláudia Lima. Ensaio para uma Introdução ao Direito Internacional Privado. In DIREITO, Carlos Alberto Menezes, TRINDADE, Antonio Augusto Cançado, PEREIRA, Antonio Celso Alves (Org.). Novas Perspectivas do Direito Internacional Contemporâneo: Estudos em Homenagem ao Professor Celso D. de Albuquerque Mello. p. 319-350. 25 "A sociedade internacional [...] ilustra a dimensão internacional das normas jurídicas do direito interno, e abriga inter-relações entre empresas e diferentes Estados". RIBEIRO, Marilda Rosado de Sá. Parecer sobre a Oitava Rodada de Licitações. In RIBEIRO, Marilda Rosado de Sá (Org.). Novos Rumos do Direito do Petróleo. p. 24.
} 
O resgate de concepção privatista, em oposição a uma teorização meramente estatal, passa pela readoção sistemática da expressão Direito das Gentes, a qual remonta à designação romana Ius Gentium ${ }^{26}$ - usada para tratar dos temas atinentes ao Direito Internacional. Após a enunciação da soberania estatal como postulado básico, na Paz de Westfália ${ }^{27}$, e o subsequente nascimento dos Estados nacionais no pós-Revolução Francesa, o Direito Internacional passou a tratar fundamentalmente das questões estatais, reconhecendo-se apenas o Estado como destinatário de normas no plano internacional. Na transição do século XIX para o XX e, em especial, após a derrota dos regimes nazifascistas, em 1945, a partir de quando se difundiram os Direitos Humanos, passou-se a reconhecer a voluntariedade e o poder de outros atores, a exemplo dos indivíduos, a moldar o plano internacional. ${ }^{28-29-30}$

26 "Os romanos tinham um profundo respeito pela organização e pelas leis. O direito unia todo o império e era um ponto de referência essencial para todos os habitantes desse gigantesco domínio. $\mathrm{O}$ direito romano primitivo (o jus civile) aplicava-se somente aos cidadãos romanos. [...] $\mathrm{O}$ jus civile era totalmente incapaz de fornecer uma estrutura adequada a uma nação em expansão e desenvolvimento. Essa necessidade foi atendida pela criação e progressiva ampliação do jus gentium, que fornecia normas simplificadas para governar as relações dos cidadãos romanos com os estrangeiros e destes entre si." SHAW, Michael N. Direito Internacional, trad. Marcelo Bandão Cipolla, Lenita Ananias do Nascimento, Antonio de Oliveira Sette-Câmara, rev. Marcelo Brandão Cipolla. p. 205.

${ }^{27}$ A Paz de Westfália pôs fim, em 1648, à Guerra dos Trinta Anos, lançando as bases para o moderno sistema estatal europeu.

28 "[...] a perda de exclusividade da ação internacional do Estado, o desafio que este passou a enfrentar com a emergência de outros atores políticos, como as ONGs, os grupos de interesses internacionais, as internacionais religiosas e as grandes corporações internacionais, bem com de outros sujeitos de direito na ordem pública mundial, como o ser humano individualmente e as organizações internacionais, acentuando que a compreensão desse quadro pós-Westfália só se daria numa perspectiva multidisciplinar." PEREIRA, João Eduardo de Alves. Geopolítica e Direito Internacional no Século XXI. In DIREITO, Carlos Alberto Menezes, TRINDADE, Antonio Augusto Cançado, PEREIRA, Antonio Celso Alves (Org.). Novas Perspectivas do Direito Internacional Contemporâneo: Estudos em Homenagem ao Professor Celso D. de Albuquerque Mello. p. 884.

29 "[...] os indivíduos compõem o conceito contemporâneo de Direito Internacional Público, ao lado dos Estados e das Organizações Internacionais intergovernamentais. A condição dos indivíduos como detentores de personalidade jurídica internacional é uma das mais notáveis conquistas do Direito Internacional Público do século XX, lograda em decorrência do processo de desenvolvimento e solidificação dos Direitos Humanos. [...] Não vemos como pode ser negada a personalidade jurídica internacional dos indivíduos atualmente, principalmente levando-se em conta o ocorrido após a eclosão da Segunda Guerra quando os indivíduos passaram a ter direitos próprios, estranhos às normas endereçadas aos Estados, tendo sido dotados, inclusive, de instrumentos processuais para vindicar e fazer valer seus direitos no plano internacional." MAZZUOLI, Valério de Oliveira. Curso de Direito Internacional Público. p. 343.

30 Embora exista uma redefinição do papel estatal, a exemplo da flexibilização da soberania definida por Celso D. de Albuquerque Mello como um feixe de competências que o Estado possui e lhe é dado pela ordem jurídica internacional, o Estado subsiste como ator decisivo; não se podendo concordar com a concepção de morte do Estado. Entre outros, Samuel Pinheiro Guimarães rechaça a concepção do ocaso estatal: "A despeito dos argumentos sobre o gradual desaparecimento do Estado e de sua substituição por organizações não-governamentais ou pelas grandes empresas transnacionais, o fato é que o Estado foi, é e continuará a ser o principal ator 
Não foram, porém, os indivíduos os únicos atores a se destacar internacionalmente nesta globalização: em relação às empresas transnacionais, faz-se imperioso chamá-las à responsabilização31, porquanto funcionam e obedecem a uma ótica própria - desterritorializada e desconexa da racionalidade dos locais em que agem.

Atuam, a partir de uma política externa própria, cunhada pelos interesses do centro de comando, onde se localiza a matriz, lançando-se aos demais mercados e segmentam a instância de tomada de decisão (na sede) do restante do mundo:

[...] como principal característica das empresas transnacionais, a capacidade de orientar, centralizadamente, as suas operações em diversos pontos do mundo, através de um planejamento global, inclusive no que diz respeito aos programas de pesquisa e de desenvolvimento e às metas financeiras, na busca pela mitigação dos custos, aumento de sua influência e expansão dos seus mercados consumidores. Nesse contexto, a referida empresa atua como se existisse um mercado mundial, no qual ela possa operar em várias localidades, de modo que os mercados nacionais são menos importantes que o mundial, no que diz respeito à tomada de decisão das empresas, sendo certo que as mesmas relativizam a preocupação com os interesses locais. O controle das filiais ou subsidiárias, em todos os aspectos, é pressuposto da coordenação de seus objetivos globais. ${ }^{22}$

Essa responsabilização, na esfera internacional, pressupõe o enquadramento desses agentes como sujeitos de Direito Internacional, titulares de direitos e vinculados a obrigações no plano supraestatal.33

A economia global, para seu melhor funcionamento, requer uma sociedade, que, por sua vez, se fundamente em sistema efetivo de Direito. As transações devem ser baseadas em instrumentos legais que propiciem confiança, e os Estados devem organizar suas competências segundo a boa governança;

do sistema internacional." GUIMARÃES, Samuel Pinheiro. Quinhentos anos de periferia. p. 53 .

${ }_{31}$ "Celso Mello soube identificar a relevância das empresas transnacionais na vida internacional, reconhecendo-as como sujeitos de direito internacional, com normas de DIP a elas dirigidas." RIBEIRO, Marilda Rosado de Sá. Parecer sobre a Oitava Rodada de Licitações. In RIBEIRO, Marilda Rosado de Sá (Org.). Novos Rumos do Direito do Petróleo. p. 26.

${ }^{2}$ RIBEIRO, Marilda Rosado de Sá. As Empresas Transnacionais e os Novos Paradigmas do Comércio Internacional. In DIREITO, Carlos Alberto Menezes, TRINDADE, Antonio Augusto Cançado, PEREIRA, Antonio Celso Alves (Org.). Novas Perspectivas do Direito Internacional Contemporâneo: Estudos em Homenagem ao Professor Celso D. de Albuquerque Mello. p. 463.

33 MELLO, Celso D. de Albuquerque. Direito Internacional Econômico. p. 103. 
mediante a promoção de controle legal do poder econômico, público ou privado, e da coibição a distorções à competição. 34

A complexidade jacente assevera a necessidade da cooperação e da coordenação, conduzidas preferencialmente por órgãos e mecanismos multilaterais. A ação concertada - balizada pelas regras de conduta de órgãos efetivamente multilaterais - outorga a legitimidade necessária à ação internacional, inclusive no plano do Direito. 35

Para Ricardo Lobo Torres, a ideia racional de uma comunidade pacífica e perpétua, formada por todos os povos da terra (mesmo quando não sejam amigos), entre os quais podem se estabelecer relações, não é um princípio filantrópico (ético), mas um princípio jurídico. Este direito, como a união de todos os povos e com relação a certas leis universais, poderia ser chamado de direito cosmopolita. Ricardo Lobo Torres vai além, e faz a defesa enfática de que o direito cosmopolita abranja os direitos humanos no espaço supranacional. A integração regional e, no caso europeu, seu corolário - a cidadania comunitária; a proteção ao meio ambiente (somente eficaz se articulada no plano transcendente aos Estados); o controle dos conflitos armados; a defesa da construção de espaços decisórios democráticos e multilaterais; o reconhecimento de fontes não estatais, e até as não governamentais, como legítimas e válidas normas internacionais; todas essas manifestações são apontadas como vetores, a impulsionar o direito cosmopolita. 36

A percepção de que fatores locais podem afetar todo o sistema internacional também reforça a necessidade de que o campo de pesquisa não

34 RIBEIRO, Marilda Rosado de Sá. Parecer sobre a Oitava Rodada de Licitações. In RIBEIRO, Marilda Rosado de Sá (Org.). Novos Rumos do Direito do Petróleo. p. 39. Em sentido distinto, dispõem, contudo, Michael J. Trebilcock e Robert Howse: "In a world where (apart from background rules of contracting) government action does not influence the allocation of productive resources, markets themselves should generate optimal levels of foreign investment. In such a world, government intervention would, almost by definition, distort the allocation of productive resources". TREBILCOCK, Michael J. e HOWSE, Robert. Regulation of International Trade. p. 443.

35 "O interesse particular, quando se projeta multilateralmente, deve estar amparado pela demonstração de que serve ao coletivo." FONSECA JR, Gelson. O Interesse e a Regra Ensaios sobre o Multilateralismo. p. 24. "Outro princípio essencial na sociedade contemporânea é o da cooperação internacional. A própria lei de coexistência entre os Estados foi substituída por uma lei internacional da cooperação.” RIBEIRO, Marilda Rosado de Sá. Parecer sobre a Oitava Rodada de Licitações. In RIBEIRO, Marilda Rosado de Sá (Org.). Novos Rumos do Direito do Petróleo. p. 29.

${ }^{36}$ TORRES, Ricardo Lobo. A Afirmação do Direito Cosmopolita. In DIREITO, Carlos Alberto Menezes, TRINDADE, Antonio Augusto Cançado, PEREIRA, Antonio Celso Alves (Org.). Novas Perspectivas do Direito Internacional Contemporâneo: Estudos em Homenagem ao Professor Celso D. de Albuquerque Mello. p. 919-940. 
mais se constranja às economias centrais e ao estudo dos ordenamentos jurídicos adotados apenas por esses países. O conceito de comunity of shared risks, como preceitua Habermas 37 , espraia-se, portanto, como um dos principais fatores para que se incorporem outros Estados no esforço de prevenção e combate de crises na esfera internacional.

\section{CONCLUSÃo}

A urgência em se responder satisfatoriamente aos desafios contemporâneos guia o Direito na atualidade. Não pode, contudo, a legitimidade das críticas às assimetrias do comércio internacional turvar a percepção de que os investimentos abarcam uma dimensão concreta, e que servem de irrenunciável estímulo econômico ao local que os recebe. E é também em relação a esse aspecto prático - associado à busca de estabilidade nas relações privadas - que o Direito Internacional oferecerá ferramentas, antecipando eventos, mitigando riscos, reduzindo a aleatoriedade das circunstâncias e estabelecendo uma previsibilidade mínima das condutas.

O reconhecimento das transnacionais como sujeito de direito internacional comporta o imperativo de responsabilização desses agentes que imprimem uma lógica própria aos diferentes locais, não raro desconexa das tradições e das necessidades nativas.

A proposta de um direito cosmopolita procura, assim, redirecionar o direito internacional a um fundamento ético, permeado indissociavelmente pelo princípio da solidariedade, que a guerra de lugares vem paulatinamente desconstruindo.

\section{REFERÊNCIAS}

BAYLIS, John et al. The Globalization of World Politics. Oxford: Oxford Press, 2009.

BENDA-BECKMAN et al. Mobile Law: an introduction. In: Mobile People, Mobile Law: Expanding Legal Relations in a Contracting World. Surrey, UK: Asggate, 2005.

DOLZER, Rudolph e SCHREUER, Christoph. Principles of International Investment Law. Oxford: Oxford University Press, 2008.

\footnotetext{
37 HABERMAS, Jürgen. Learning by Disaster? A Diagnostic Look back on The Short
} Twentieth Century. p. 317. 
FONSECA JR, Gelson. O Interesse e a Regra - ensaios sobre o multilateralismo. Brasília: Paz e Terra, 2008.

GUIMARÃES, Samuel Pinheiro. Quinhentos Anos de Periferia. 5. ed. Rio de Janeiro: Contraponto, 2007.

HABERMAS, Jürgen. Learning by Disaster? a diagnostic look back on the short twentieth century. Constellations 5, n. 3, 1998.

HOBSBAWM, Eric. Globalização, Democracia e Terrorismo. São Paulo: Companhia das Letras, 2007.

JAYME, Erik. Identité Culturelle et Intégration: le droit internationale prive postmoderne. Curso de Haia de 1995.

LAFER, Celso. O Impacto de um Mundo em Transformação no Direito Internacional. In DUPAS, Gilberto; LAFER, Celso e DA SILVA, Carlos Eduardo Lins. A Nova Configuração do Poder Mundial. São Paulo: Paz e Terra, 2008.

MARQUES, Cláudia Lima, Ensaio para uma Introdução ao Direito Internacional Privado. In DIREITO, Carlos Alberto Menezes, TRINDADE, Antonio Augusto Cançado, PEREIRA, Antonio Celso Alves (Org.). Novas Perspectivas do Direito Internacional Contemporâneo: estudos em homenagem ao Professor Celso D. de Albuquerque Mello. Rio de Janeiro: Renovar, 2008.

MAZZUOLI, Valério de Oliveira. Curso de Direito Internacional Público. 2. ed. São Paulo: Editora Revista dos Tribunais, 2007.

MELLO, Celso D. Albuquerque. Direito Internacional Econômico. Rio de Janeiro: Renovar, 2003.

OLIVEIRA, Henrique Altemani e LESSA, Antônio Carlos. Política Internacional Contemporânea: mundo em transformação. São Paulo: Saraiva, 2006.

PEREIRA, João Eduardo de Alves. Geopolítica e Direito Internacional no Século XXI. In DIREITO, Carlos Alberto Menezes; TRINDADE, Antonio Augusto Cançado, PEREIRA, Antonio Celso Alves (Org.). Novas Perspectivas do Direito Internacional Contemporâneo: estudos em homenagem ao Professor Celso D. de Albuquerque Mello. Rio de Janeiro: Renovar, 2008.

RIBEIRO, Marilda Rosado de Sá; ALMEIDA, Bruno. A Cinemática Jurídica Global: Conteúdo do Direito Internacional Privado Contemporâneo. Revista da Faculdade de Direito da UERJ, Rio de Janeiro, v.1, n. 20, 2011.

RIBEIRO, Marilda Rosado de Sá. As Empresas Transnacionais e os Novos Paradigmas do Comércio Internacional. In DIREITO, Carlos Alberto Menezes; TRINDADE, Antonio Augusto Cançado; PEREIRA, Antonio Celso Alves (Org.). Novas Perspectivas do Direito Internacional Contemporâneo: estudos em homenagem ao Professor Celso D. de Albuquerque Mello. Rio de Janeiro: Renovar, 2008.

Parecer sobre a Oitava Rodada de Licitações. In RIBEIRO, Marilda Rosado de Sá (Org.). Novos Rumos do Direito do Petróleo. Rio de Janeiro: RENOVAR, 2009.

SANTOS, Milton e SILVEIRA, Maria Laura. O Brasil, Território e Sociedade no Início do Século XXI. 10. ed. São Paulo: Record, 2008. 
SANTOS, Milton. Por Uma Outra Globalização - do pensamento único à consciência universal. 15. ed. São Paulo: Record, 2008.

SHAW, Michael N. Direito Internacional. Tradução de Marcelo Bandão Cipolla, Lenita Ananias do Nascimento, Antonio de Oliveira Sette-Câmara, rev. Marcelo Brandão Cipolla. São Paulo: Martins Fontes, 2010.

TORRES, Ricardo Lobo. A Afirmação do Direito Cosmopolita. In DIREITO, Carlos Alberto Menezes, TRINDADE, Antonio Augusto Cançado, PEREIRA, Antonio Celso Alves (Org.). Novas Perspectivas do Direito Internacional Contemporâneo: estudos em homenagem ao Professor Celso D. de Albuquerque Mello. Rio de Janeiro: Renovar, 2008.

TREBILCOCK, Michael J. e HOWSE, Robert. Regulation of International Trade. New York: Taylor and Francis Group, 2005. 